\title{
The application of zinc citrate for the synthesis of carbon materials
}

\author{
Yuliya Sinelnikova ${ }^{1,2}$ and Nikolai Uvarov ${ }^{1,2}$ \\ ${ }^{1}$ Institute of Solid State Chemistry and Mechanochemistry SB RAS, 630090 Novosibirsk, Russia \\ ${ }^{2}$ Novosibirsk State Technical University, 630073 Novosibirsk, Russia
}

\begin{abstract}
Zinc citrate was prepared and its thermal decomposition was investigated by methods of thermogravimetric analysis and differential scanning calorimetry. Products of the thermal decomposition were investigated by X-ray diffraction analysis. The decomposition proceeds at temperatures $50-420{ }^{\circ} \mathrm{C}$ in three stages and leads to the formation of nanocrystalline $\mathrm{ZnO}$ with the average grain size of $23 \mathrm{~nm}$. Subsequently, zinc citrate was used as a precursor of $\mathrm{ZnO}$ hard template for preparation of carbon mesoporous materials by the solid template method. The carbon materials were obtained by pyrolysis of polymer matrix of phenolformaldehyde resin in which zinc citrate was added. It was found that the resulting material has a specific surface area of $1051 \mathrm{~m}^{2} / \mathrm{g}$. According to the cyclic voltamperometry data, the material has a specific capacity $40 \mathrm{~F} / \mathrm{g}$.
\end{abstract}

\section{Introduction}

Porous carbon materials are widely applied in various fields of science and technology. Due to their high specific surface area, high electrical conductivity, chemical inertness and the possibility of varying the pore size, they can be used as adsorbents, catalyst carriers, electrode materials in supercapacitors, etc. $[1,2]$. Intensive research is underway worldwide to develop safe and commercially available methods for the synthesis of porous carbon materials. The most suitable method of all known methods is template synthesis using solid template agents which can be used to obtain materials with different pore sizes [3]. But even in this case, difficulties associated with the choice of a solid template arise. The literature mainly describes the methods of synthesis using different forms of mesoporous silicon dioxide as templates [4], but its removal from the material is expensive [5]. Besides silicon oxides, zeolites [6] and metal oxides may be also used as hard templates. Recently magnesium citrate and acetate have been proposed to be precursors for in-situ formation of solid templates for synthesis of mesoporous carbon [7]. However, the mechanism of the oxide template formation and optimal concentrations of the precursors are to be elucidated yet. Therefore, the search for suitable templates and the optimization of preparation conditions for the preparation of mesoporous carbon materials remains an urgent task. Zinc oxide can be considered as one of the solid template for preparation of carbon mesoporous materials. Zinc oxide may be easily removed from the final product by acid treatment and may be prepared by thermal decomposition of the zinc salt precursors. 
In this work, zinc citrate $\mathrm{Zn}_{3}\left(\mathrm{C}_{6} \mathrm{H}_{5} \mathrm{O}_{7}\right)_{2} \cdot \mathrm{xH}_{2} \mathrm{O}$ was used as a precursor for the synthesis of mesoporous carbon materials. Zinc citrate is a white granular powder, odorless, nontoxic and cheap compound. In order to understand the conditions of formation of zinc oxide from the precursors, zinc citrate was prepared, characterized and its decomposition products were studied.

\section{Experimental part}

The synthesis of zinc citrate was carried out using the exchange reaction of zinc oxide and citric acid. The estimated amount of zinc oxide was added by small portions to the aqueous citric acid solution. The precipitate of zinc citrate $\mathrm{Zn}_{3}\left(\mathrm{C}_{6} \mathrm{H}_{5} \mathrm{O}_{7}\right)_{2} \cdot \mathrm{xH}_{2} \mathrm{O}$ was obtained after evaporation of water solvent at $90{ }^{\circ} \mathrm{C}$. The resulting zinc citrate is a white powder, insoluble in water and ethyl alcohol. Decomposition of zinc citrate was investigated in the temperature range $25-600{ }^{\circ} \mathrm{C}$. The decomposition products were collected after heating the initial compound at temperatures of $170{ }^{\circ} \mathrm{C}, 250{ }^{\circ} \mathrm{C}, 320{ }^{\circ} \mathrm{C}, 350{ }^{\circ} \mathrm{C}$ and $420{ }^{\circ} \mathrm{C}$ for $1 \mathrm{~h}$ at each temperature.

To obtain porous carbon materials, the powder of zinc citrate was added to the initial solution used for the polymerization of phenol-formaldehyde resin in a molar ratio of zinc citrate: phenol equal to 1: 5. Polymerization was carried out in an alcohol solution at a temperature of $100{ }^{\circ} \mathrm{C}$ for 2 days. Then the resulting mixture was subjected to pyrolysis in an inert argon atmosphere at a heating rate of $5{ }^{\circ} \mathrm{C} / \mathrm{min}$ up to $900{ }^{\circ} \mathrm{C}$. The resulting material was treated with a hydrochloric acid solution to remove the formed zinc oxide and washed with distilled water. The final product was a black powder.

To study the characteristics of the obtained zinc citrate, the methods of thermal gravimetry (TG) and differential scanning calorimetry (DSC) analysis and powder X-ray diffraction were used. Thermal analysis was carried out with synchronous thermal analyzer STA $449 \mathrm{~F} / 1 / 1$ JUPITER at a heating rate of $10 \mathrm{~K} / \mathrm{min}$ in an atmosphere of pure argon or in a mixture of $60 \% \mathrm{Ar}-40 \% \mathrm{O}_{2}$. X-ray diffraction experiments were carried out using a $\mathrm{X}$-ray powder diffractometer $\mathrm{D} 8$ Advance using $\mathrm{Cu} \mathrm{K} \alpha$ radiation $(\lambda=0.1542 \mathrm{~nm})$ in the range of $2 \theta$ angles from $10^{\circ}$ to $75^{\circ}$. Adsorption properties of the carbon materials were studied using the analysis of BET isotherms of nitrogen adsorption at $77 \mathrm{~K}$ with an analyzer "Termosorb TPD1200".

\section{Results and Discussion}

\subsection{Thermal decomposition of zinc citrate}

Figure 1 shows the data of thermogravimetric analysis and differential scanning calorimetry of the obtained zinc citrate in an atmosphere of a mixture of argon and oxygen. As seen, the decomposition includes three stages. In the first stage the dehydration takes place at 25 $250{ }^{\circ} \mathrm{C}$ :

$$
\mathrm{Zn}_{3}\left(\mathrm{C}_{6} \mathrm{H}_{5} \mathrm{O}_{7}\right)_{2} \cdot x \mathrm{H}_{2} \mathrm{O}=\mathrm{Zn}_{3}\left(\mathrm{C}_{6} \mathrm{H}_{5} \mathrm{O}_{7}\right)_{2}+x \mathrm{H}_{2} \mathrm{O}
$$

According to the thermal analysis data, the relative change in the mass, $90 \%$ corresponds to the $x$ value of 2.1. Therefore, the formula of the prepared compound is $\mathrm{Zn}_{3}\left(\mathrm{C}_{6} \mathrm{H}_{5} \mathrm{O}_{7}\right)_{2} \cdot 2 \mathrm{H}_{2} \mathrm{O}$ in agreement with the literature data. From X-ray data presented in Fig. 2, one can see that in the temperature range of $25-250{ }^{\circ} \mathrm{C}$ the crystal structure of citrate remains unchanged, despite of the considerable water loss. 


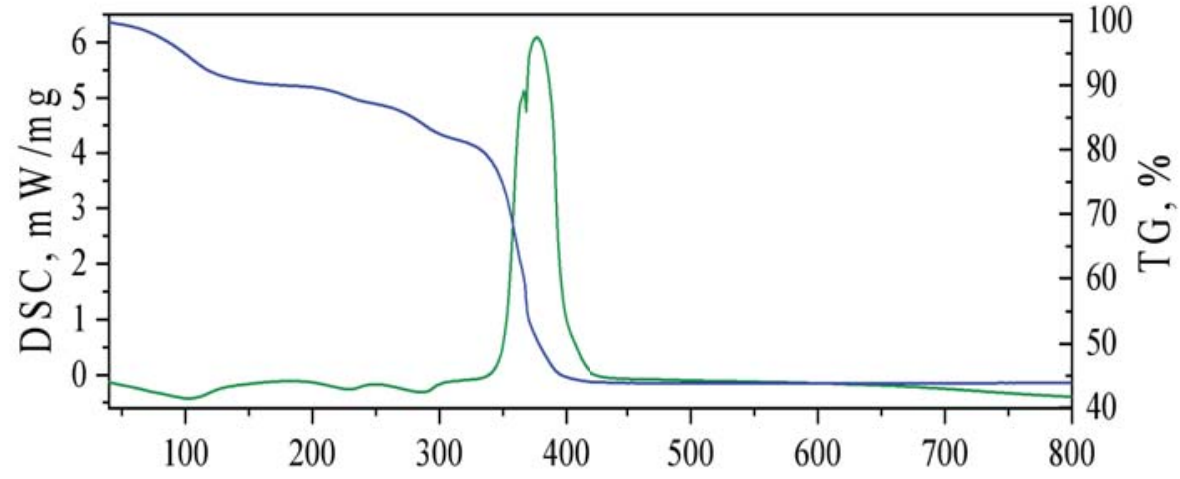

Temperature, ${ }^{0} \mathrm{C}$

Fig. 1. TG and DSC of the starting zinc citrate.

In the second stage at $250-320^{\circ} \mathrm{C}$ thermal decomposition of anhydrous zinc citrate takes place with formation of various X-ray amorphous organic salts, such as zinc zis- and transaconitate, citroconate, etc. and zinc carbonate [8]. This stage is accompanied by an endothermic effect.

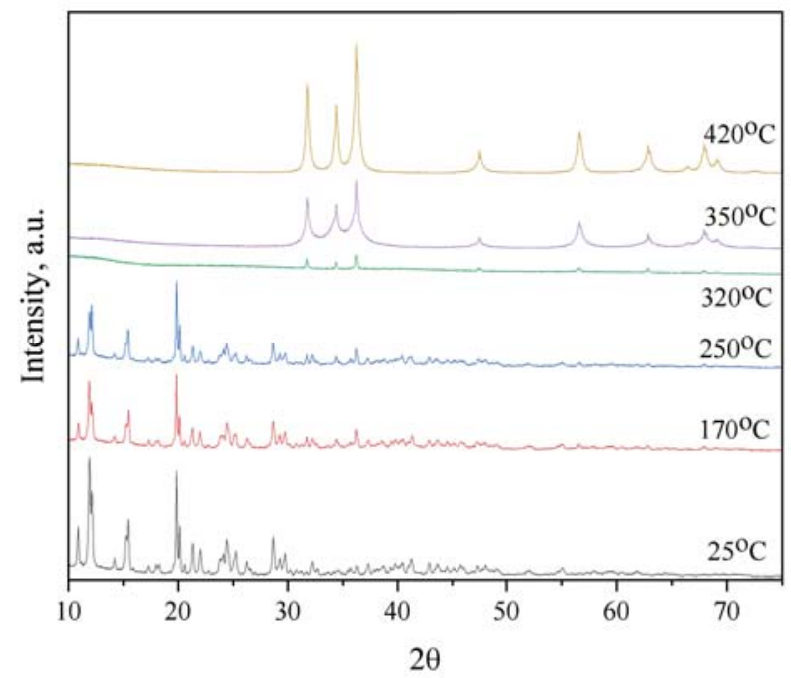

Fig. 2. X-ray diffraction patterns of the initial zinc citrate and products of its thermal decomposition.

On the last stage at temperatures above $320{ }^{\circ} \mathrm{C}$ the organic salts decompose with formation of zinc carbonate and are oxidized by oxygen with formation of $\mathrm{CO}_{2}$ and $\mathrm{H}_{2} \mathrm{O}$. This process is strongly exothermic. In parallel, zinc carbonate decomposes with formation of zinc oxide $\mathrm{ZnO}$ accompanied a sharp endothermic effect. Summary reaction may be written as follows

$$
\mathrm{Zn}_{3}\left(\mathrm{C}_{6} \mathrm{H}_{5} \mathrm{O}_{7}\right)_{2} \cdot 2 \mathrm{H}_{2} \mathrm{O}+9 \mathrm{O}_{2}=3 \mathrm{ZnO}+12 \mathrm{CO}_{2}+7 \mathrm{H}_{2} \mathrm{O}
$$

with the relative change in the mass of $44 \%$, that is close to the theoretical value of $42 \%$. The resulting zinc oxide has a grain size of about $23 \mathrm{~nm}$. In the course of synthesis, this oxide may act as a template agent. 


\subsection{Investigation of the obtained carbon mesoporous materials}

The product of pyrolysis of phenol-formaldehyde resin with additive of zinc citrate precursor was treated with a hydrochloric acid solution to remove the formed zinc oxide and washed with distilled water. The final product was a black powder which was investigated by adsorption and voltammetric methods.

The nitrogen adsorption experiments showed that the specific surface area of the sample estimated from BET isotherms of nitrogen adsorption reached $1051 \mathrm{~m}^{2} / \mathrm{g}$. This value exceeds ones obtained for carbon materials synthesized using $\mathrm{SiO}_{2}$-based hard templates [4] and comparable to values prepared using MgO-based templates [9].

Figure 3 shows the cyclic voltammetry (CV) curves obtained for an electrode material consisting of 80 wt \% porous carbon material and 20 wt. \% Carbon Black. A symmetrical two-electrode cell was used for testing. $1 \mathrm{M}$ sulfuric acid aqueous solution was used as electrolyte. Voltage scan was performed at scan rates of $5,10,20,50$, and $100 \mathrm{mV} / \mathrm{s}$. It is seen, that all CV curves have a shape typical to electrodes which are characterized by the formation of an electric double layer and the absence of Faraday reactions on the surface of the material. However, the calculated values of the specific capacity is rather small and not exceeds $40 \mathrm{~F} / \mathrm{g}$. Possible reasons of small specific capacitance values of the material could be small pore size or hydrophobic character of the surface of the material. Further studies are needed to improve the electrochemical performance of the materials under study.

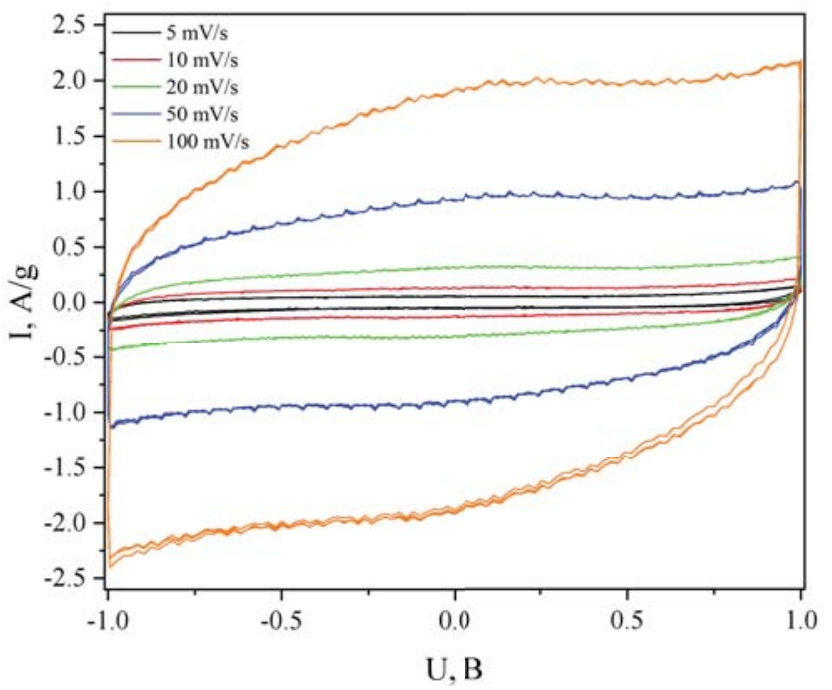

Fig. 3. Voltammograms of the electrode material consisting of the obtained porous carbon material at potential sweep rates of $5,10,20,50$, and $100 \mathrm{mV} / \mathrm{s}$.

\section{Conclusions}

In this work zinc citrate was obtained using an exchange reaction and its physico-chemical properties were studied by methods of X-ray phase analysis, thermogravimetric analysis and scanning differential calorimetry. The resulting zinc citrate was used as a precursor generating the template agent $\mathrm{ZnO}$ in the course of pyrolysis of phenol-formaldehyde resin. The carbon material with a high specific surface area of $1051 \mathrm{~m}^{2} / \mathrm{g}$ was obtained. Electrochemical properties of the obtained carbon material were investigated and the specific capacity of $40 \mathrm{~F} / \mathrm{g}$ in the acidic electrolyte was estimated. 
Authors thank L.I. Brezhneva for the help in synthesis, Dr. K.B. Gerasimov for TG and DSC investigations. The work was supported by Government State Assignment, project FWUS -2021-0007 and Thematic plan of NSTU, project TP-HHT-1_21.

\section{References}

1. K. Wang, Y. Wang, Y. Wang, E. Hosono, H. Zhou, J. Phys. Chem. C, 113, 1093 (2008)

2. A.C. Power, B. Gorey, S. Chandra, J. Chapman, Nanotechnol. Rev. 7, 19 (2018)

3. Z. Zhang, F. Zuo, P. Feng, J. Mater. Chem. 11 (2010)

4. T. Kyotani, T. Nagai, S. Inoue, A. Tomita, Chem. Mater. 9, 609 (1997)

5. S. Ungureanu, M. Birot, H. Deleuze, V. Schmitt, N. Mano, R. Backov, Carbon, 91, 311 (2015)

6. H. Noh, S. Choi, H.G. Kim, M. Choi, H-T. Kim, Chem. Electro. Chem. 6, 558 (2019)

7. T. Morishita, T. Tsumura, M. Toyoda, J. Przepiórski, A.W. Morawski, H. Konno, M. Inagaki, Carbon, 48, 2690 (2010)

8. Seham A.A. Mansour, Thermochimica Acta, 233, 231 - 242 (1994)

9. W. Liu, C. Wang, J. Wang, F. Jia, J. Zheng, M. Chen, Chin. Sci. Bull. 58, 992 (2013) 